\title{
III. Gobierno y democracia
}




\title{
Jurisdicción constitucional y consolidación de la democracia
}

\author{
DiETER NOHLEN ${ }^{*}$ \\ dieter.nohlen@urz.uni-heidelberg.de
}

\begin{abstract}
Artículo recibido 05/02/2008
Evaluación par externo 27/02/2008

Evaluación par interno 10/03/2008
\end{abstract}

\section{Resumen}

Este articulo analiza la relación entre jurisdicción constitucional y consolidación de la democracia. Se ocupa, en primer lugar, de la multidimensionalidad de los factores que influyen en la consolidación de la democracia y la relativa importancia de los tribunales constitucionales en este proceso; en segundo lugar expone la multidimensionalidad de los conceptos de democracia y de consolidación de la democracia y la relevancia que dentro de los diferentes conceptos alcanza la jurisdicción constitucional; tercero, apunta a la interrelación reciproca entre democracia y jurisdicción constitucional, destacando el carácter politico de su relación. Por lo demás, hace bincapie en la tesis de que, respecto a esta relación y explicando casos, ¿el contexto hace la diferencia? Se enfoca enseguida en las funciones de la jurisdicción constitucional. Se dedica, primero, a los requisitos irrenunciables que tienen que darse y las condiciones favorables que fomentan el cumplimiento de sus funciones porparte de los tribunales constitucionales, y segundo, entra en algunos ámbitos de la jurisdicción constitucional en búsqueda de su relevancia para la consolidación de la democracia. Finalmente, termina afirmando el carácter circular de la relación entre jurisdicción constitucional y consolidación de la democracia,

\footnotetext{
* Agradezco el apoyo de José Reynoso Núñez en la revisión de este estudio.
} 


\title{
116 / Dieter Nohlen
}

resumiendo algunas de las afirmaciones que de manera diferenciada se han becho a lo largo del estudio.

Palabras clave: consolidación de la democracia, tribunales constitucionales, democracia constitucional, democracia representativa, democracia participativa, procesos constituyentes, reformas constitucionales, reformas electorales.

\section{Constitutional Jurisdiction and Consolidation of Democracy}

\begin{abstract}
This article analyzes the relationship between constitutional jurisdiction and consolidation of democracy, highlighting first of all the multidimensionality of the factors that influence the consolidation of democracy and the relative importance of the constitutional court in this process; stating secondly the multidimensionality of the concepts of democracy and consolidation of democracy as well as the relevance reached by the constitutional jurisdiction within the different concepts; and thirdly, aiming at the reciprocal interrelationship between democracy and constitutional jurisdiction, emphasizing the political nature of such relationship. In all other respects, the question stressed in the thesis is, with respect to this relationship and detailing certain cases: ¿does context make a difference? Then, the focus shifts towards the role of the constitutional jurisdiction. First, it looks at the inalienable requirements that must be present and the conditions favorable to the promotion of the constitutional courts' fulfillment of their roles, and secondly, it touches on some aspects of constitutional jurisdiction in search of its relevance regarding the consolidation of democracy. Finally, the circular characteristic of the relationship between constitutional jurisdiction and consolidation of democracy is affirmed, summarizing some of the assertions that have been made distinguishably throughout the study.
\end{abstract}

Key words: Consolidation of democracy, constitutional courts, constitutional democracy, representative democracy, participative democracy, constituent reform, electoral reform. 


\section{Introducción}

El título de mi conferencia abre una perspectiva de análisis que es típica para investigaciones politológicas. Consiste en establecer una relación causal entre los fenómenos enfocados, es decir, aquí, entre la jurisdicción constitucional y la consolidación de la democracia. ¿Cuál es el efecto que tiene la jurisdicción constitucional sobre la consolidación de la democracia? De forma análoga, la ciencia política ha estudiado la relación causal entre sistemas electorales y sistemas de partidos políticos, llegando a precisar en qué condiciones la variable independiente ejerce tales $\mathrm{u}$ otros efectos sobre la variable dependiente. ${ }^{1}$ ¿Podemos proceder analíticamente de forma parecida respecto a nuestro tema de hoy? ¿Podemos esperar llegar a semejantes alcances, aunque la relación parezca más compleja y como tal menos susceptible a mediciones empíricas?

La pregunta parece aun más pertinente dado que nuestro tema está prácticamente ausente en la literatura politológica. Las consideraciones sobre la consolidación de la democracia se refieren al mundo de las democracias de la tercera ola, y respecto a este grupo de países raras veces involucran la jurisdicción constitucional como objeto relevante. En el ámbito del derecho público sí encontramos este tipo de referencias, ${ }^{2}$ incluso en rápido aumento, las cuales, sin embargo, se caracterizan por su grado de generalización y una tendencia a sobre o subestimar la importancia de la jurisdicción constitucional en sus efectos sobre la consolidación de la democracia. ${ }^{3}$

Nuestro conocimiento proveniente de la experiencia nos dice que la relevancia de una variable tratada como independiente respecto a otra dependiente, en el campo de las ciencias humanas, es siempre relativa. Así, en la primera parte de mi conferencia, me dedicaré a la

\footnotetext{
${ }^{1}$ Véase Nohlen, D., Sistemas electorales y partidos politicos, $3^{a}$ edición, México, Fondo de Cultura Económica, México, D.F., 2004.

${ }^{2}$ Esto es especialmente cierto respecto a la relación entre la democracia y el constitucionalismo, como destaca Pedro Salazar en la introducción a mi libro Derecho y politica en su contexto, UNAM et. al., México, D.F., 2008.

${ }^{3}$ Para México, véase el interesante estudio empírico de Cristina Begné Guerra, Jueces y democracia en México, Miguel Ángel Porrúa, México, D.F., 2007.
} 


\section{8 / Dieter Nohlen}

multidimensionalidad del problema, refiriéndome a los factores que influyen en el proceso de la consolidación de la democracia. Por experiencia sabemos también que la relación enfocada depende de los conceptos que se aplican, en nuestro caso, del concepto de democracia y del concepto de consolidación que tengamos. En este sentido, en segundo lugar, introduciré la multidimensionalidad de los conceptos y la relevancia que dentro de los diferentes conceptos alcanza la jurisdicción constitucional. Nuestro conocimiento proveniente de la experiencia nos dice, además, que a menudo se establecen interdependencias entre las variables observadas. Así, en tercer lugar, mis consideraciones apuntarán a la interrelación recíproca (Wechselwirkung) entre democracia y jurisdicción constitucional, destacando el carácter político de su relación. Por último, por experiencia sabemos que el contexto importa. Tal vez conozcan mi escrito El contexto hace la diferencia, publicado por el Instituto de Investigaciones Jurídicas de la Universidad Autónoma de México (UNAM) ${ }^{4}$ en el que hice énfasis en la necesidad de diferenciación ${ }^{5}$ entre instituciones y contexto, demostrando además cómo el contexto interviene en los efectos que exhiben las instituciones. ${ }^{6}$ Lo mismo puede hacerse valer para el derecho. Como apunta José Afonso da Silva, "la misma norma o el mismo texto normativo tiene un sentido o significado diferente cuando está situado en contextos diferentes". Enfocando en seguida las funciones de la jurisdicción constitucional, me dedicaré, primero, a los requisitos irrenunciables que tienen que darse y las condiciones favorables que fomentan el cumplimiento de sus

\footnotetext{
${ }^{4}$ Nohlen, D., El contexto hace la diferencia, UNAM, México, D.F., 2003.

${ }^{5}$ Conforme con Spencer-Brown, G., Laws of Form, Allen \& Unwin, Londres, 1969.

${ }^{6}$ Véase también Nohlen, D., El institucionalismo contextualizado. La relevancia del contexto en el análisis y diseño institucionales, Porrúa - UNAM, México, D.F., 2006; Ortiz Ortiz, R., "Contextos, instituciones y actores políticos. Dieter Nohlen y el estudio de las instituciones políticas en América Latina", en Nohlen, D., El institucionalismo contextualizado. La relevancia del contexto en el análisis y diseño institucionales, op. cit., pp. 1-30, y Ortiz Ortiz, R. \& Reynoso Núñez, J., "Dieter Nohlen y el estudio de la democracia y las instituciones políticas en América Latina", en López Rubí Calderón, J. R. (coord.), Política y ciencia política en Dieter Noblen, Benemérita Universidad Autónoma de Puebla, Puebla, 2007, pp. 17-57.

${ }^{7}$ Alfonso da Silva, J., Comentário contextual à constituição, Malheoros, Sao Paulo, 2005, p. 17; Véase también Häberle, P., "La Constitución 'en el contexto" ", en Anuario Iberoamericano de Justicia Constitucional, 2003, pp. 223-246; Serna de la Garza, J. M. (coord.), Metodología de derecho comparado. Memoria del Congreso Internacional de Culturas y Sistemas Jurídicos Comparados, UNAM, México, D.F., 2005; Serna de la Garza, J. M. (coord.), Derecho comparado Asia-México. Culturas y sistemas jurídicos comparados, UNAM, México, D.F., 2007.
} 
funciones por parte de los tribunales constitucionales, y segundo, entraré en algunos ámbitos de jurisdicción constitucional en búsqueda de su relevancia para la consolidación de la democracia. Finalmente, terminaré mi charla afirmando el carácter circular de la relación entre jurisdicción constitucional y consolidación de la democracia, resumiendo algunas de las afirmaciones que de manera diferenciada se han hecho con respecto a ella.

De este programa se desprende que — aunque siendo institucionalista - no me va interesar hoy el diseño institucional de los tribunales constitucionales (su modelo, su composición, sus competencias, sus reglas procesales, que obviamente difieren según los casos y sin lugar a duda tienen efectos relevantes), sino su relación funcional en el sistema y en el proceso político. Tampoco nos interesa aquí el origen kelseniano o austriaco de la jurisdicción constitucional y la diferencia de su versión europea con el judicial review estadounidense, objetos tantas veces tratados y recapitulados en recientes trabajos comparativos. ${ }^{8}$ El enfoque funcionalista tiene en su centro el papel real de la jurisdicción constitucional en el sistema político. ${ }^{9}$ Su aplicación se ve aun más fundamentada por la reciente tendencia en el derecho público de tematizar no tanto el Estado, ni el Estado de derecho, ni el Estado

\footnotetext{
${ }^{8}$ Véase el Anuario Iberoamericano de Justicia Constitucional y la Revista Iberoamericana de Derecho Procesal Constitucional, así como los recientes libros colectivos sobre la materia, por ejemplo García Belaúnde, D. y Fernández Segado, F. (coords.), La jurisdicción constitucional en Iberoamérica, Dykinson et al., Madrid, 1997; Ferrer Mac-Gregor, E. (coord.), Interpretación constitucional, 2 tomos, Porrúa - UNAM, México, D.F., 2005; Palomino Manchego, J. F. (coord.), El derecho procesal constitucional peruano. Estudios en homenaje a Domingo García Belaunde, 2 tomos, Grijley, Lima, 2005. Véase también entre otros Fix-Fierro, H., "Poder judicial", en Del Refugio, M. \& López Ayllón, S. (eds.), Transiciones y diseños institucionales, UNAM, México, D.F., 1999, pp. 167-224; García Belaúnde, D. (coord.), La Constitución y su defensa, Grijley, Lima, 2003; García Belaúnde, D., Elpoder judicial en la encrucijada, Ara, Lima, 2004; Lösing, N., Die Verfassungsgerichtsbarkeit in Lateinamerika, Nomos, Baden-Baden, 2001 (existe versión castellana bajo el extraño título: La jurisdiccionalidad constitucional en Latinoamérica, Dykinson, Konrad Adenauer Stiftung, Madrid, 2002); Nogueira Alcalá, H. (coord.), Jurisdicción constitucional en Chile y América Latina: presente y perspectiva, LexisNexis, Santiago, 2005; Fix-Fierro, H., Tribunales, justicia y eficiencia. Estudio sociojurídico sobre la racionalidad económica en la función judicial, UNAM, México, D.F., 2006.

${ }^{9}$ Grimm, D., "Jurisdicción Constitucional", en Nohlen, Dieter, et al. (eds.), Diccionario de Ciencia Política. Teorías, métodos, conceptos, 2 tomos, Porrúa - El Colegio de Veracruz, México, 2006, p. 793.
} 


\section{0 / Dieter Nohlen}

social, sino el Estado constitucional en sus dimensiones funcionales. ${ }^{10}$ De igual manera, se observa en la ciencia política la tendencia de tematizar no el Estado, sino las instituciones y la estructura institucional, o sea, de observar lo público en un nivel en el que es posible precisar más los objetos de estudio y tratarlos como variables en su interrelación causal. Así, los tribunales constitucionales se encuentran en el mismo nivel de las demás instituciones constitucionales (aunque la jurisdicción constitucional en América Latina no siempre tiene un estatus autónomo, separado de la jurisdicción ordinaria).

\section{Multidimensionalidad de los factores en el proceso de consolidación}

En el caso de la relación entre sistemas electorales y sistemas de partidos, intervienen factores de contexto que explican por qué no existe una relación lineal entre ambos fenómenos. En el caso que estudiamos hoy, tampoco se da este tipo de relación causal. Existen varios factores muy relevantes que a su manera pueden tener altísima importancia para la consolidación de la democracia, incluso para el tipo de régimen político. Comparando estos factores, el papel de los tribunales constitucionales parece débil. Sin embargo, esta consideración no debería irritarnos, pues conforme a la teoría del caos, factores de primer orden por sí mismos no tienen que ejercer necesariamente grandes efectos, mientras que mínimas modificaciones provenientes de factores secundarios pueden tenerlos, percibidos sobre todo si el análisis integra perspectivas de mediano o largo alcance. Por otra parte, si nos damos cuenta de la multidimensionalidad de factores que influyen en el proceso de la consolidación democrática en América Latina y del reducido papel de los tribunales constitucionales, nos protegemos frente a la exageración de la importancia atribuida a la jurisdicción constitucional en este proceso, cuya parte concomitante podría resultar en sobrecargarla con funciones que sencillamente no puede cumplir.

\footnotetext{
${ }^{10}$ Véase Valadés, D. \& Carbonell, M. (coords.), El Estado constitucional contemporáneo. Culturas y sistemas jurídicos comparados, 2 tomos, UNAM, México, D.F., 2006; Salazar Ugarte, P., La democracia constitucional. Una radiografía teórica, Fondo de Cultura Económica, IIJ-UNAM, México, D.F., 2006.
} 
En las explicaciones causales que se han dado en la literatura científica para el problema de la consolidación de la democracia en la región, se puede distinguir a grandes rasgos entre (1) la hipótesis de la carencia económica que apunta al insuficiente desarrollo económico, sustentada por la teoría de la modernización; ${ }^{11}$ (2) la hipótesis de la carencia social, que se enfoca en la persistencia de la pobreza y la desigualdad social; ${ }^{12}$ (3) la hipótesis de la carencia política, que se basa en los déficits de la democracia de no cumplir, sobre los cuales los informes sobre el desarrollo humano de las agencias de desarrollo llaman continuamente la atención; (4) la hipótesis de la carencia político-institucional que hace hincapié en los problemas estructurales de los sistemas políticos, hipótesis con mayor consenso en el mundo académico, como señala por ejemplo el estudio del Programa de las Naciones Unidas para el Desarrollo (PNUD) ${ }^{13}$ sobre la democracia en América Latina; (5) la hipótesis de la falta de confianza de la población en la democracia como el orden político preferido y en la satisfacción con los resultados de la política; ${ }^{14}$ (6) la hipótesis de la carencia de capital social que focaliza la sociedad y su capacidad de generar confianza en los otros. Según esta última tesis tiene que existir una cierta medida de confianza interpersonal para formar una comunidad eficiente, cuyo progreso económico y social pueda producir un sistema político consolidado. ${ }^{15}$

En comparación con la variable jurisdicción constitucional, no cabe duda de que los seis factores o grupos de factores enumerados alcan-

\footnotetext{
${ }^{11}$ Jaguaribe, H., Political Development. A General Theory and a Latin American Case Study, Harper \& Row, New York, 1973; Pasquino, G., Modernización y desarrollo politico, Nova Terra, Barcelona, 1974; Graciarena, J. \& Franco, R., Social Formation and Power Structures in Latin America, Sage, Londres - Beverly Hills, 1978.

${ }^{12}$ Midlarsky, M. I. (ed.), Inequality, democracy, and economic development, Cambridge University Press, Cambridge, 1997; Lamounier, B., "Brazil: Inequalities against Democracy", en Diamond, L. et al. (eds.), Democracy in Developing Countries: Latin America, Lynne Rienner, Boulder, 1999, pp. 131-189.

${ }^{13}$ Programa de las Naciones Unidas para el Desarrollo (PNUD), Democracy in Latin America. Towards a Citizens' Democracy, Aguilar, Buenos Aires, 2004.

${ }^{14}$ Véase Latinobarómetro de 1996 en adelante. Latinobarómetro, 1996-2006, entregas anuales, Santiago de Chile.

${ }^{15}$ Putnam, R. D., Making Democracy Work: Civil Traditions in Modern Italy, Princeton University Press, Princeton, 1993.
} 
zan un valor explicativo mayor para el problema de la consolidación democrática. De esta manera no debe sorprender que la jurisdicción constitucional — como ya decía antes- casi no entra en las consideraciones politológicas sobre la consolidación de la democracia en América Latina. Véanse por ejemplo el libro más citado, el de Linz y Stepan ${ }^{16}$ sobre democratización y consolidación de la democracia; la exhaustiva compilación de David Potter y otros sobre "democratization"; ${ }^{17}$ el estudio de J. Mark Payne y otros ${ }^{18}$ titulado La politica importa, así como el informe del PNUD $^{19}$ sobre el desarrollo de la democracia en América Latina. ${ }^{20}$ Por cierto, se debate el control de las instituciones, especialmente del Ejecutivo, y la manera de poner límites al ejercicio del poder. Pero entran en escena por sobre todo la sociedad civil y los medios de comunicación como principales actores garantes del poder limitado. Por lo demás, se debate el ejercicio del poder tal cual, no tanto el ejercicio del poder conforme a las normas constitucionales.

\section{Multidimensionalidad de los conceptos}

En el caso del sistema de partidos, existe un alto grado de consenso sobre el concepto y sus dimensiones, que hay que tomar en cuenta a la hora de medir el efecto que el sistema electoral tenga sobre el mismo. ${ }^{21}$ En el caso de los conceptos de democracia y de consolidación

\footnotetext{
${ }^{16}$ Linz, J.J. y Stepan, A., Problems of Democratic Transition and Consolidation, Johns Hopkins University Press, Baltimore, 1996.

${ }^{17}$ Potter, D.; Goldblatt, D.; Kiloh, M. \& Lewis, P. (eds.), Democratization, Polity Press, Cambridge, 1997. Es importante señalar que en los trabajos de la perspectiva predominante en la ciencia política, el poder judicial en el transcurso de la democratización gana importancia como objeto (como variable dependiente), pero no es tratado como actor (como variable independiente) de los procesos de democratización o consolidación de la democracia.

${ }^{18}$ Payne, J.M.; Zovatto, D.; Carrillo Flórez, F. \& Allamand, A., La política importa. Democraciay desarrollo en América Latina, Banco Interamericano de Desarrollo, Washington, D.C., 2003.

${ }^{19}$ PNUD, Democracy in Latin America. Towards a Citizens' Democracy, op. cit.

${ }^{20}$ Para el caso mexicano, véase también, entre otros, Galeana, P. (comp.), El camino de la democracia en México, Archivo General de la Nación, México, D.F., 1998; Ortega Ortiz, R. Y., Caminos a la democracia, El Colegio de México, México, D.F., 2001, y Woldenberg, J., La construcción de la democracia, Plaza y Janés, México, D.F., 2002.

${ }^{21}$ Véase Nohlen, Sistemas electorales y partidos políticos, op. cit.; y Zilla, C., "Los conceptos en el enfoque politológico de Dieter Nohlen”, en López Rubí Calderón, J. R. (coord.), Política y ciencia política en Dieter Noblen, Benemérita Universidad Autónoma de Puebla, Puebla, 2007, pp. $75-100$.
} 
de la democracia no es así. Respecto a nuestras consideraciones, lo importante es que la ambivalencia conceptual existente tiene altísima importancia sobre el posible efecto que puede atribuirse a la jurisdicción constitucional en la vida política, así como a su medición y evaluación.

Si se define la democracia a la manera de Alain Touraine como "la lucha de los sujetos, en su cultura y en su libertad, contra la lógica dominadora de los sistemas", ${ }^{22}$ la jurisdicción forma parte del sistema a combatir. Cuando lo sustantivo de la democracia es la deconstrucción de su propia institucionalidad, no interesa la jurisdicción constitucional, o sólo interesa desde un punto inverso, para pasar por encima de su función en el proceso de liberación. Si se entiende la democracia en su sentido radical, de democracia directa, como la entienden algunos intelectuales y aquellos actores que quieren sustituir la democracia representativa por la así llamada democracia participativa, la jurisdicción constitucional tiene una importancia relativa, subordinada a la toma de decisiones por parte del soberano popular, que en cada momento puede imponerse sobre la constitución vigente y sus supuestos guardianes. Si se entiende la democracia en su sentido representativo, ${ }^{23}$ entonces la jurisdicción constitucional sí puede jugar un rol importante, sobre todo si se identifica la democracia representativa con la democracia constitucional, tendencia que en los últimos años ha recuperado fuerza ante la extensión del uso de los conceptos de contraste.

El concepto de la consolidación democrática, por su parte, es también multidimensional y muy controvertido, vinculado por lo demás con diferentes conceptos de legitimidad. Leonardo Morlino ${ }^{24}$ veía en

\footnotetext{
${ }^{22}$ Touraine, A., ¿Podemos vivir juntos ?, Fondo de Cultura Económica, Buenos Aires, 1997, p. 114.

${ }^{23}$ Para este y otros conceptos de la democracia véase Nohlen et al. (eds.), Diccionario de Ciencia Politica. Teorías, métodos, conceptos, op cit., pp. 338-356. Véase también Macpherson, C. B., La democracia liberaly su época, Alianza, Madrid, 1982; Starck, Ch. (ed.), Constitutionalism, Universalism and Democracy. A Comparative Analysis, Nomos, Baden-Baden, 1999; Viola, F., La democracia deliberativa entre constitucionalismo y multiculturalismo, UNAM, México, D.F., 2006.

${ }^{24}$ Morlino, C., "Consolidación democrática. Definición, modelos, hipótesis", en Revista Española de Investigaciones Sociológicas, $\mathrm{N}^{\circ}$ 35, 1986, pp. 7-61.
} 
1986 la consolidación como un proceso que tiene como consecuencia la continua adaptación de los actores políticos a las reglas del juego democrático y, con ello, la continua ampliación de la legitimidad ${ }^{25}$ del orden político establecido. En el marco de este inicial concepto de consolidación que se fija en los actores políticos, es fácil ubicar y evaluar alto el rol de la jurisdicción constitucional: mantener encarriladas sus acciones, en el caso dado, a lo que la constitución prescribe. Diez años más tarde, Juan J. Linz y Alfred Stepan ${ }^{26}$ distinguían ya entre varias dimensiones del problema de la consolidación: (1) la dimensión conductual: ningún actor político, social o económico persigue sus objetivos con medios que tengan como consecuencia el establecimiento de un sistema no democrático; (2) la dimensión actitudinal: una gran mayoría de la opinión pública mantiene la valoración de la democracia como la mejor forma de gobierno, aunque esté insatisfecha con los logros de los gobiernos democráticos; (3) la dimensión constitucional: tanto el gobierno como la oposición se someten a la constitución y solucionan sus conflictos en el marco de las reglas de juego del sistema político. Se observan grandes diferencias del rol y posible impacto de la jurisdicción constitucional en la consolidación según las dimensiones señaladas. En las dos primeras es extremamente relativo, para no decir quantité negligable. Sólo en la última dimensión, llamada constitucional, la jurisdicción constitucional encuentra su enlace de forma muy explícita con el proceso de consolidación democrática.

\footnotetext{
${ }^{25}$ La pretensión de legitimidad de un orden político apunta a un concepto normativo del mismo. Se puede entender como cualidad objetiva de un sistema social o sistema político (por ej., la legitimidad que se le atribuye como inherente a un sistema político democrático en el marco de los horizontes mentales correspondientes, o la legitimidad entendida como el mantenimiento de la legalidad) o estar basada en escalas normativas externas, respecto a las cuales se compara esta pretensión. De acuerdo con esto, la legitimidad puede ser definida como: (1) la coincidencia de un orden político con el derecho, en el cual está garantizada la realización de determinados principios (en la democracia, pluralismo político, derechos democráticos de participación, Estado de derecho, etc.); o (2) la capacidad de un orden político de ser reconocido como legítimo, por lo cual la pretensión de un sistema político de gozar de legitimidad sólo existe cuando las expectativas de comportamiento elevadas a norma expresan intereses capaces de ser generalizados (Cfr. Habermas, J., Problemas de legitimación en el capitalismo tardio, $3^{\mathrm{a}}$ edición, Amorrortu, Buenos Aires, 1989; véase también Heidorn, J., Legitimität und Regierbarkeit [Legitimidad y gobernabilidad], Duncker \& Humblot, Berlín, 1982).

${ }^{26}$ Linz y Stepan, Problems of Democratic Transition and Consolidation, op. cit., p. 30.
} 
En la trilogía de dimensiones de Andreas Schedler, ${ }^{27}$ finalmente, no se sostiene de igual manera este vínculo. Schedler, tras una amplia revisión de los diferentes enfoques, destaca tres modelos de enfocar el problema de la consolidación: (1) el procesual, en el que se afirma o no si las democracias son capaces de imponerse y dominar los desafíos antidemocráticos; (2) el actitudinal, orientado a la élite política, en el sentido de que sus miembros, y sobre todo los gobiernos, desarrollan normativamente los valores democráticos, diseñan estrategias racionales y desarrollan las habilidades necesarias para mantener la democracia; y (3) el orientado a las bases socioeconómicas, en el sentido de que su desarrollo sea propicio para la continuidad democrática. Ninguna de estas dimensiones es apta para poner de relieve la función de la jurisdicción constitucional para la consolidación democrática. Incluyendo la dimensión económica en el problema de la consolidación de la democracia, Schedler reintroduce no sólo una variable de alto valor explicativo cuya carrera en ciencias sociales se remonta a los orígenes de la teoría de la modernización, sino una variable que en nuestro contexto destaca por dos características: primero, es la variable con menores probabilidades de sufrir efectos provenientes de decisiones de los tribunales constitucionales en su manera de incidir en la consolidación de la democracia, y segundo, es probablemente la variable más susceptible a la medición en sus efectos sobre la consolidación democrática, de modo que facilita marcar diferencias en la medición de efectos de distintos factores causantes de la consolidación. En el caso de la variable económica se observa precisamente una correlación positiva entre las tasas de crecimiento económico y el grado de satisfacción con la democracia, como señalan las encuestas. ${ }^{28}$ Podemos concluir que el desempeño del gobierno importa. Es el rendimiento político el que aumenta la legitimidad de salida (output legitimacy) de la democracia y así su consolidación. Respecto al desempeño, la jurisdicción constitucional, como vamos a ver a continuación, puede aportar algo, aunque este algo será siempre difícil de medir. Por lo demás, es casi imposible establecer correlaciones directas y medibles entre jurisdicción constitucional y valoración

\footnotetext{
${ }^{27}$ Schedler, A. "Los cálculos de consolidación democrática", en Republicana:politicay sociedad, 2002, p. 20.

${ }^{28}$ Véase Latinobarómetro, 2006.
} 


\section{6 / Dieter Nohlen}

o consolidación de la democracia. Por otra parte, se excluye también que la baja en la aceptación de la democracia que se pudo observar en el último decenio sea un efecto directo de la actuación (mal evaluada) de la jurisdicción constitucional. En otros términos, tampoco existe una relación causal determinante de índole negativa entre jurisdicción constitucional y consolidación de la democracia.

\section{La relación interdependiente de los factores}

Estas observaciones invitan a llamar la atención sobre otro conocimiento proveniente de la experiencia, que apunta a la relación recíproca de los fenómenos. Incluso en el estudio de la relación causal entre sistema electoral y sistema de partidos se observan efectos circulares: el propio sistema de partidos tiene influencia sobre el efecto que tiene el sistema electoral sobre el mismo. Este tipo de interdependencia es mucho más fuerte en la relación que estudiamos, especialmente por el hecho de que la jurisdicción constitucional, así como el derecho público en general, están percibidos como eminentemente políticos, o sea dependientes de factores que provienen de la política. ${ }^{29}$ Jorge Carpizo y Héctor Fix-Zamudio ${ }^{30}$ apuntan precisamente a esta reciprocidad, cuando dicen que "a través del derecho constitucional el derecho penetra y se introduce en la vida de la comunidad y a su vez los factores políticos, sociales y económicos determinan en buena parte el derecho constitucional". Aun más, con la creación de órganos de jurisdicción constitucional ha entrado un nuevo actor en la escena política. Respecto a su rol, Dieter Grimm" enfatiza que "la jurisdicción constitucional no sólo hace valer en el caso concreto las decisiones generales previas de la constitución, sino que toma también decisiones políticas por su cuenta. Puesto que muchas veces estas decisiones tienen como objeto el comportamiento de los órganos superiores del Estado y de los partidos políticos que actúan

\footnotetext{
${ }^{29}$ Sagués, N.P., El tercer poder. Notas sobre el perfil político del poder judicial, LexisNexis, Buenos Aires, 2005; Fix-Zamudio, H., "Justicia constitucional y judicialización de la política”, en Orozco Henríquez, J. J. (coord.), Sistemas de justicia electoral. Evaluación y perspectivas, IFE PNUD, México, D.F., 2001, pp. 11-38.

${ }^{30}$ Carpizo, J. \& Fix-Zamudio, H., "Algunas reflexiones sobre la interpretación constitucional en el ordenamiento mexicano", en Ferrer Mac-Gregor, E. (coord.), Interpretación constitucional, 2 tomos, Porrúa, México, D.F., 2005, tomo 1, p. 424.

${ }^{31}$ Grimm, D., op. cit., p. 793.
} 
en ellos, la jurisdicción constitucional participa, si se aplican criterios funcionales, en la dirección del Estado". Siendo los tribunales constitucionales instituciones políticas como las demás, aunque de legitimidad democrática secundaria y carentes de un aparato propio para hacer ejecutar sus decisiones, ellos disponen de importantes funciones en el proceso político, con capacidad de decisión última en asuntos de alta importancia en el juego político. Dolf Sternberger ${ }^{32}$ puntualizó: "El derecho es en sí mismo un eminente factor político".

En la perspectiva de la teoría de los jugadores de veto, ${ }^{33}$ los tribunales constitucionales constituyen jugadores de veto institucionales dentro del sistema político. Aunque en principio de racionalidad propia, pueden articularse dentro de ellos jugadores de veto individuales (o sea, los miembros de los tribunales) asociados con los partidos políticos, de modo que se puede imponer la lógica de competencia política que a su vez puede determinar decisiones en pro o en contra de otras instituciones del sistema político, especialmente referidas a la voluntad política del gobierno. Es por esto que se establece otra circularidad: al control constitucional que ejercen los tribunales sobre el Ejecutivo se añade el intento por parte de los partidos políticos y especialmente del gobierno de hacerse del control del tribunal constitucional.

En la perspectiva de la teoría sistémica ${ }^{34}$ se trata de una relación entre el sistema político con su propia racionalidad, la racionalidad del poder, y de la jurisdicción constitucional con la suya, la racionalidad del derecho, o sea entre un (marcado) sistema y su entorno. Según el enfoque de la autopoiésis, ${ }^{35}$ la incidencia que tiene el factor externo, aquí la jurisdicción constitucional, es dependiente de la estructura del sistema, aquí el sistema político, y del comportamiento de los actores

\footnotetext{
${ }^{32}$ Sternberger, D., Lebende Verfassung [Constitución viviente], Verlag Anton Hain, Meisenheim, 1956, p. 24.

${ }^{33}$ Tsebelis, G., Veto Players. How Political Institutions Work, Russell Sage Foundation, Princeton University Press, Princeton, New Jersey, 2002.

${ }^{34}$ Véanse Münch, R., "Teorías de sistemas", en Nohlen et al., Diccionario de Ciencia Politica. Teorías, métodos, conceptos, op cit., pp. 1389-1395; Luhmann, N., Soziale Systeme [Sistemas sociales], Frankfurt, Suhrkamp, 1984.

${ }^{35}$ Véase Maturana, H. y Varela, F., Der Baum der Erkenntnis [El árbol del conocimiento], Scherz, Bern, 1984.
} 


\section{8 / Dieter Nohlen}

institucionales. Las decisiones de los tribunales constitucionales, en general (en el lenguaje sistémico) de efecto "irritante", pueden ser interpretadas como "estimulantes" y de esta manera asumidas por los actores, o percibidas como "perturbadoras". La última percepción puede conducir a que el sistema (político) trate de compensarlas o impedir su cumplimiento o tomar las precauciones pertinentes (por ejemplo, la sustitución de magistrados) para que no se repitan situaciones "perturbadoras" debido a decisiones de los tribunales constitucionales.

De todos modos, resulta claro que la influencia del factor externo nunca será determinante, sino relativa conforme a las estructuras del sistema y las mentalidades de sus actores. Dentro de esta perspectiva sistémica es posible marcar diferencias entre sistemas susceptibles de reaccionar de acuerdo con la percepción "estimulante" o "perturbadora" de la labor de la jurisdicción constitucional. Respecto a esta disyuntiva, la mayor diferencia que se impone es aquella entre democracias consolidadas y democracias que aún viven el problema de su consolidación. Mientras que el primer grupo de países se puede asociar con una interpretación "estimulante", el segundo grupo de países tiende a una percepción "perturbadora”. Otras diferencias pueden referirse a características de menor calibre que pueden ser transversales a la anterior categorización en grupos de países, por ejemplo una cultura de toma de decisiones jerárquica-decisionista, así como el presidencialismo ${ }^{36}$ y el bipartidismo. Estas mentalidades y estructuras son especialmente proclives al intervencionismo político en la esfera de la jurisdicción constitucional, que por lo demás hace

\footnotetext{
${ }^{36}$ Respecto al debate sobre el presidencialismo en América Latina, véase Nohlen, D. \& Fernández, M. (eds.), Presidencialismo versus parlamentarismo. América Latina, Editorial Nueva Sociedad, Caracas, 1991; Linz, J.J. \& Valenzuela, A. (eds.), The Failure of Presidential Democracy, 2 vols, JHUP, Baltimore - Londres, 1994; Nohlen, D. \& Fernández, M. (eds), Elpresidencialismo renovado, Nueva Sociedad, Caracas, 1998; Jesse, E. \& Nohlen, D., "Presidencialismo/Sistema presidencial", en Nohlen et al., Diccionario de Ciencia Política. Teorías, métodos, conceptos, op cit., pp. 1114-1117. Respecto al presidencialismo méxicano y su reforma véase Carpizo, J., El presidencialismo méxicano, Siglo XXI, México, D.F., 1978; Nohlen, D., "La renovación del presidencialismo: reformas institucionales y gobernabilidad democrática”, en El institucionalismo contextualizado. La relevancia del contexto en el análisis y diseño institucionales, op. cit., pp. 67-80; Carpizo, J., Concepto de democracia y sistema de gobierno en América Latina, UNAM, México, D.F., 2007; Valadés, D., La parlamentarización de los sistemas presidenciales, UNAM, México, D.F., 2007.
} 
bien visible la interrelacionalidad de los fenómenos observados. Inversamente, todos los atributos de la civilidad, o sea "comprensión, moderación y gentileza, cualidades basadas en la estima y el respeto a otras personas", ${ }^{37}$ son favorables a la jurisdicción constitucional en su efecto sobre la consolidación de la democracia, aunque lo son también directamente para tal objetivo. Esta concordancia estriba en que "el pluralismo de los equilibrios dinámicos que se nutre de moderación, reconocimiento, respeto y diálogo recíprocos", de eminente importancia para el desarrollo democrático, constituye también "el objetivo más profundo de los tribunales constitucionales". ${ }^{38}$

Un aspecto relevante para el efecto de la consolidación de la democracia que se espera de la jurisdicción constitucional, es crear y mantener cierto grado de independencia de los tribunales constitucionales frente a los demás actores. Además, para que se mejore el funcionamiento del sistema político y progrese la consolidación de la democracia, el aumento de la cantidad de jugadores de veto en un sistema político requiere que los principales actores políticos desarrollen comportamientos más acordes con el modelo de consenso de toma de decisiones. Me parece que México se encuentra actualmente en esta encrucijada. Otro aspecto relevante consiste en modificar la percepción de las decisiones jurisdiccionales por parte de los actores políticos de "perturbadora" en "estimulante". Sin embargo, el proceso de la consolidación involucra a ambos lados. En la democracia constitucional el fin de la Constitución y la función de la jurisdicción constitucional no deben agotarse - acorde con la vieja tensión entre Estado y sociedad en América Latina- en limitar al gobierno, sino tienen que posibilitar y fomentar el gobierno democrático capaz de atender a las demandas de la gente, procurando mayor legitimidad de salida al sistema de gobierno y apoyando por este camino a la consolidación de la democracia. Es el camino más seguro para propiciar relevancia a su propio quehacer.

\footnotetext{
${ }^{37}$ Como lo definía en otro lugar, véase Nohlen et al., Diccionario de Ciencia Politica. Teorías, métodos, conceptos, op. cit., p. 204.

${ }^{38}$ Zagrebelsky, G., "Jueces constitucionales", en Revista Iberoamericana de Derecho Procesal Constitucional, $\mathrm{N}^{\circ} 2006$, p. 324. Respecto a los conceptos de política y su relevancia para la jurisdicción constitucional, véase también Córdova Vianello, L., "La contraposición entre derecho y poder desde la perspectiva del control de constitucionalidad en Kelsen y Schmitt", en Cuestiones Constitucionales, N 15, 2006, pp. 47-68.
} 


\section{Funciones de la jurisdicción constitucional}

En términos generales, existe alto consenso sobre la función de la jurisdicción constitucional, de modo que no conviene demorarme en ese tema en este foro de especialistas en la materia. Sin embargo, conviene puntualizar que en principio, su función no es ni debe ser de forma directa la consolidación de la democracia por la simple razón que ya hemos dado a entender: tan exigente objetivo depende de tantos otros factores mucho más importantes, de modo que los tribunales constitucionales, en caso de peligros de derrumbe inminente, son obviamente incapaces de contrarrestar o contener el proceso.

Esta tesis no se ve deslegitimada por el reciente análisis de Ahumada Ruiz ${ }^{39}$ quien afirma que la garantía de la Constitución no ha sido nunca la principal función de los tribunales constitucionales. Ella considera que su contribución más notable se ha producido en el plano político y tiene que ver con su participación en la consolidación del sistema de democracia constitucional, orientando la actuación de los poderes públicos y ayudando a generar usos y comportamientos democráticos tanto en el ejercicio del poder como en la sociedad. Esta tesis presupone, sin embargo, la definitiva consolidación de la democracia según patrones del constitucionalismo democrático. La realidad política de América Latina es otra y no confirma el análisis: persisten los retos a la democracia, y últimamente se han extendido especialmente aquellos referidos a la democracia constitucional, como vamos a ver en adelante. Nuevamente el contexto hace la diferencia. Ex ante de la consolidación democrática, la incertidumbre sobre su desenlace no permite un balance tan determinante de la actuación de los tribunales constitucionales.

Conviene, además, cuidarse en individualizar demasiado las funciones de la jurisdicción constitucional, pues con la precisión se expone su actuación a nivel empírico a una prueba que no pasa fácilmente de forma positiva. Por ejemplo, es cierto que la jurisdicción constitucional puede contribuir a la extensión de valores democráticos, pero

\footnotetext{
${ }^{39}$ Ahumada Ruiz, M., La jurisdicción constitucional en Europa. Bases teóricas y politicas, Universidad de Navarra-Civitas, Navarra, 2005, pp. 302 y ss.
} 
tampoco conviene establecerlo como objetivo directo, sino como efecto colateral deseado. De otra manera, la medición de la aceptación de la democracia como norma que ha exhibido una tendencia a la baja en América Latina en el último decenio ${ }^{40}$ podría figurar como prueba empírica del fracaso de la jurisdicción constitucional en este su desempeño.

El posible aporte de la jurisdicción constitucional a la consolidación de la democracia puede resultar como efecto inherente del desempeño de su función principal: cuidar el cumplimiento de las normas de la Constitución por parte de los órganos públicos. La Constitución escrita puede adquirir en la vida de la sociedad una importancia bastante mayor. ${ }^{41} \mathrm{El}$ cumplimiento de esta función está vinculado a diferentes condiciones externas que interactúan con la jurisdicción constitucional.

\section{Requisitos y condiciones para la jurisdicción constitucional}

Si hemos llegado a este punto de hacer depender la jurisdicción constitucional de factores políticos, económicos y sociales, conviene indagar estos factores, que quisiera diferenciar entre prerrequisitos irrenunciables y condiciones favorables, como se dan en América Latina hoy.

\subsection{Requisitos irrenunciables}

Respecto a los requisitos irrenunciables, quisiera mencionar primero la existencia de un Estado constitucional. La jurisdicción constitucional presupone la constitucionalidad de la estructura del Estado. Sin constitución en el sentido material del concepto no habrá constitucionalidad ni jurisdicción constitucional. Los respectivos requisitos son bien conocidos: derechos humanos, principio democrático, separación de poderes, como mínimo. Sólo el establecimiento de un Estado constitucional hace posible el control de concordancia con la norma

\footnotetext{
${ }^{40}$ Véanse las entregas anuales desde 1996 de Latinobarómetro.

${ }^{41}$ Véase Hesse, K., "La jurisprudencia y la jurisdicción constitucional”, en Revista Iberoamericana de Derecho Procesal Constitucional, N 4, 2005, pp. 157-168.
} 


\section{2 / Dieter Nohlen}

del proceso político y de las decisiones emanadas de este proceso. Imponiendo límites al ejercicio del poder, este control puede tener efectos positivos sobre la consolidación de la democracia. Por lo demás, el Estado constitucional sustrae determinados principios consustanciales con sí mismo a decisiones a través del proceso democrático, limitando las modificaciones constitucionales y garantizando a través de las así llamadas "cláusulas de eternidad" la identidad del Estado constitucional. Así, el tipo de Estado constitucional ha comenzado según Peter Häberle ${ }^{42}$ — a "institucionalizar" y a "constitucionalizar" el proceso constituyente, anteriormente concebido como "salvaje", "originario", que comenzaba explosivamente desde "cero".

Como observamos en América Latina, mientras se ha establecido el Estado constitucional en términos formales, en términos materiales sigue siendo una aspiración. Recientemente se escuchan voces que lo menosprecian, argumentando que un sistema de democracia constitucional con una Constitución sustrae determinadas materias a la decisión a través del proceso democrático y delega en los jueces la competencia para decidir sobre el contenido y alcance de ciertos derechos considerados fundamentales, y apuntando que la democracia constitucional constituye "una opción por un sistema de democracia restringida, rebajada, más limitada y no de democracia sustantiva". ${ }^{4}$ Al mismo tiempo se observan reformas constitucionales y procesos constituyentes que sobrepasan la constitucionalidad del orden político y el respectivo control por parte de órganos pertinentes.

El segundo requisito irrenunciable consiste en que tiene que tratarse de una democracia. Ya hemos señalado las diferencias en el concepto de democracia. Quisiera estar bien claro en que la condición irrenunciable consiste en la existencia de una democracia representativa, que se define — según Robert $\mathrm{Dahl}^{44}$ — por la participación a través de elecciones libres y por el pluralismo político a través de la competencia entre diferentes partidos políticos para llenar los mandatos de representación y para ocupar los puestos de gobierno. Se podría

\footnotetext{
${ }^{42}$ Häberle, P., El Estado constitucional, UNAM, México, D.F., 2001, p. 289.

${ }^{43}$ Ahumada Ruiz, La jurisdicción constitucional en Europa. Bases teóricas y políticas, op. cit., p. 125.

${ }^{44}$ Dahl, R., Poliarchy. Participation and Opposition, Yale University Press, New Haven, 1971.
} 
evocar también a Norberto Bobbio, ${ }^{45}$ con su definición de la democracia como un conjunto de reglas de procedimiento para la formación de decisiones colectivas, sin decir nada del contenido o resultado de las mismas. ${ }^{46}$ Cuando se introducen principios, contenidos y funciones en la definición, lo importante en nuestro contexto es que se relativiza con la importancia de las reglas también la de cuidar por su cumplimiento. Recientemente, un constitucionalista ${ }^{47}$ atribuía a la democracia la principal función de "asegurar la libertad de los individuos frente al Estado". De allí concluía que "el sujeto protagónico es el individuo participativo". Y seguía argumentando que es necesario promocionar una nueva ciudadanía, centrada en la participación y la cultura política democrática para la consolidación de estos sistemas. Así, decía que la participación está íntimamente ligada al acceso en la toma de decisiones en los asuntos políticos y tiene como función legitimar los sistemas políticos democráticos. Estas ideas parecen inocentes pero sirven de antesala para postular un concepto de democracia diferente que recientemente se está articulando en forma de la democracia participativa. Sus protagonistas no se restringen a pedir que se introduzcan mecanismos de democracia directa en la democracia representativa, experiencia que han vivido ya muchos países con mayor o menor éxito. ${ }^{48} \mathrm{La}$ idea que se promueve es sustituir la democracia representativa por una de tipo participativo. Repito: la jurisdicción constitucional sólo tiene sentido en una democracia constitucional, con garantías constitucionales de los derechos humanos y los derechos políticos, con separación de poderes dentro de un Estado de derecho, un bloque de constitucionalidad que antecede las decisiones que pueda tomar el pueblo a través de los canales de participación directa. Si al contrario, en una democracia participativa, toda estructura y decisión están su-

\footnotetext{
${ }^{45}$ Bobbio, N., El futuro de la democracia, Fondo de Cultura Económica, México, D.F., 1996; y del mismo autor, Liberalismo y democracia, Fondo de Cultura Económica, México, D.F., 1985.

${ }^{46}$ Véase Salazar Ugarte, P., La democracia constitucional. Una radiografía teórica, op. cit., pp. 136 y ss.

${ }^{47}$ Núñez Muñoz, I. K., "La ciudadanía y su desempeño en los sistemas políticos democráticos”, en Cuestiones Politicas, N³7, 2007, p. 52.

${ }^{48}$ Para América Latina véase Valadés, D., Constitución y democracia, UNAM, México, D.F., 2000, pp. 39-44; Valadés, D. (ed.), Gobernabilidad y constitucionalismo en América Latina, UNAM, México, D.F., 2005; y Zovatto, D., "Las instituciones de democracia directa”, en Nohlen, Zovatto, Orozco y Thompson (comps.), Tratado de derecho electoral comparado de América Latina, 2 a edición, Fondo de Cultura Económica, México, 2007, pp. 134-161.
} 


\section{4 / Dieter Nohlen}

jetas al veredicto del soberano popular, incluso de liquidar derechos integrantes del bloque de constitucionalidad, de abdicar a la democracia y de establecer una dictadura, ${ }^{49}$ no habrá jurisdicción constitucional. El tribunal constitucional sería una farsa, como demuestra ya el caso venezolano, donde la Sala Constitucional del Tribunal Nacional de Justicia se declaró incompetente en asuntos de su competencia o interpreta actos obviamente inconstitucionales como legitimados por el proceso que este país actualmente pasa de una democracia representativa a otra participativa. ${ }^{50}$ Sin embargo, no es necesario citar casos extremos. Cuando el Ejecutivo convoca a un referendo, sin haber cumplido con los requisitos constitucionales - por ejemplo, el de disponer del apoyo mayoritario, a veces calificado del parlamento- y el tribunal (Conseil Constitutionelle) se declara incompetente - como ocurrió en Francia en el referendo sobre la introducción de la elección directa del presidente en 1958, propulsado por el general de Gaulle- el resultado del referendo, si es positivo, es considerado capaz de curar la inconstitucionalidad de su origen. La democracia directa permite legitimar acciones inconstitucionales ex post. ¿Qué importancia le queda para el control de constitucionalidad por un respectivo tribunal? En resumen, concuerdo con Diego Valadés: ${ }^{51}$ el control del poder únicamente existe en un sistema constitucional de orden democrático-representativo.

Como tercer requisito irrenunciable quisiera estipular que la jurisdicción constitucional tiene que ser establecida de tal forma, a lo mejor autónoma, que pueda cumplir efectivamente con sus funciones. En América Latina es notable el desarrollo de la jurisdicción constitucional en los últimos dos decenios. Se refleja también en el auge de la jurisdicción constitucional como materia académica. Sin embargo, la autonomía de los órganos pertinentes sigue cuestionada. Se obser-

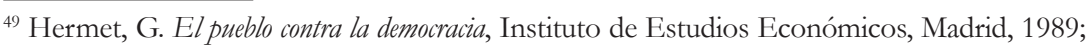
Hermet, G., En las fronteras de la democracia, Fondo de Cultura Económica, México, 1996; Bobbio, N., Democracy and Dictatorship, Polity Press, Cambridge, 1981.

${ }^{50}$ Véase Nohlen, D. \& Nohlen, N., "El sistema electoral alemán y el Tribunal Constitucional Federal. La igualdad electoral a debate - con una mirada a Venezuela", en Revista de Derecho Público, 109, enero-marzo de 2007, Caracas, pp. 7-26.

${ }^{51}$ Valadés, D., El control del poder, Fondo de Cultura Económica, México, D.F., 1998, pp. 17 y 43.
} 
van luchas por el control político de los tribunales, intervencionismo del Ejecutivo, sustitución de jueces que toman decisiones adversas al poder en ejercicio. ${ }^{52}$ La defensa de la constitución queda al margen sobre todo por procesos constituyentes que recientemente se han constituido en América Latina como el mecanismo más eficaz de cambio de las relaciones de poder.

\subsection{Condiciones favorables}

Junto a las condiciones irrenunciables, hay que considerar condiciones que pueden fomentar el buen ejercicio de las funciones de la jurisdicción constitucional. La primera condición favorable que me viene en mente es la existencia de un Estado de derecho. En este foro no hace falta defender más esta opción. Por otra parte, se podría argumentar — como lo hace Jorge Carpizo en su último libro ${ }^{53}$ — que el Estado constitucional y el Estado de derecho forman un insoluble conjunto, aunque "el Estado de derecho no es siempre la misma cosa". ${ }^{44} \mathrm{Sin}$ embargo, frente a la desconfianza que siguen teniendo los pueblos respecto al poder judicial — como consta en las encuestas de Latinobarómetro y en sondeos nacionales ${ }^{55}$ - es tal vez conveniente diferenciar entre jurisdicción normal y jurisdicción constitucional, pues esta última como órgano político en competencia con otros de origen democrático necesita este tipo de legitimidad para cumplir con sus funciones.

\footnotetext{
${ }^{52}$ Me permito citar el caso de la presidenta del Tribunal Constitucional boliviano, del que se pudo leer en la prensa internacional, sin comentario contextual alguno, a finales de octubre de 2007, justo cuando se dictó esta conferencia: "La presidenta del Tribunal Constitucional y otra magistrada renunciaron al cargo denunciando presuntas presiones y después de que el presidente Evo Morales les iniciara a ellas y a otros dos jueces un juicio por prevaricato en mayo pasado. Elizabeth Iñiguez, presidenta del tribunal, y la magistrada Martha Rojas, presentaron sus cartas de renuncia [...] al vicepresidente Álvaro García, quien también preside el Congreso Nacional. Iñiguez denunció una 'agresión permanente' a las actividades del órgano pero no identificó a los autores. Estuvo en el cargo nueve años".

${ }^{53}$ Carpizo, J., Concepto de democracia y sistema de gobierno en América Latina, UNAM, México, D.F., 2007, pp. 99 y ss.

${ }^{54}$ Zagrebelsky, "Jueces constitucionales", op. cit., p. 312.

${ }^{55}$ Véase también Ahrens, H. \& Nolte, D. (coords.), Rechtsformen und Demokratieentwicklung in Lateinamerika [Sistemas de derecho y desarrollo de la democracia], Vervuert, Francfort, 1999.
} 


\section{6 / Dieter Nohlen}

La segunda condición favorable consiste en la permanencia del orden constitucional. Para que la Constitución pueda formar una referencia con autoridad, es necesario que tenga continuidad. Si los órganos, cuyos actos tienen que ser controlados por la jurisdicción constitucional respecto a su concordancia con la norma, pueden modificar la constitución según les conviene, la función descrita es en el fondo obsoleta. Por lo demás, "una Constitución que sobrevive con incesantes modificaciones se degrada al nivel de una ley ordinaria y la materia constitucional se confunde con la lucha política cotidiana". ${ }^{56} \mathrm{De}$ la continuidad de la Constitución dependen otras condiciones de la efectividad de la jurisdicción constitucional, por ejemplo el desarrollo de una cultura de constitucionalidad, tal vez el factor más importante para el ejercicio del poder conforme a la Constitución, más importante tal vez que la propia Carta. Es por eso que algunos países no tienen ni Constitución ni jurisdicción constitucional, pero cumplen con el criterio de un Estado democrático constitucional. La continuidad de las Constituciones es — como demuestra una comparación sencilla entre Europa y América Latina- tremendamente dependiente del contexto.

Estas consideraciones no involucran un concepto estático de la Constitución. Como señala la teoría sistémica, para que el sistema cumpla con su función clave de sobrevivir, tiene que modificarse constantemente. Las Constituciones no son inertes, viven también su vida, lo que se ha expresado en el concepto de Constitución viviente (lebende Verfassung), "s7 "sensible a las exigencias constitucionales del tiempo que cambia". En términos generales, las adaptaciones a los tiempos cambiantes pueden producirse por diferentes caminos. El más ostentoso es el de las reformas constitucionales (me refiero a reformas sustanciales y no a modificaciones de menor rango que suelen también producirse), aunque resultan a veces caminos bastante complicados por los procedimientos especiales que se contemplan en las Constituciones para conservar la continuidad normativa.

\footnotetext{
${ }^{56}$ Zagrebelsky, "Jueces constitucionales", op. cit., p. 318.

${ }^{57}$ Sternberger, Lebende Verfassung, op. cit.

${ }^{58}$ Zagrebelsky, "Jueces constitucionales", op. cit., p. 316.
} 
Estas precauciones a menudo conducen a efectos contraproducentes en términos de que desencadenan un proceso de sustitución de la Constitución inerte por una nueva, iniciado por un referendo y el siguiente establecimiento de un constituyente, en el que se pierde todo sentido de continuidad..$^{59}$ Últimamente, este proceso, resultante de las crisis de gobernabilidad democrática en Venezuela, Bolivia y Ecuador, tiende a la demolición institucional de las instituciones de la democracia representativa y del Estado de derecho, sin que la jurisdicción constitucional tenga medios para impedirlo. ${ }^{60}$

El otro camino es el de la interpretación constitucional por parte de los jueces constitucionales. ${ }^{61}$ Es un proceso por cierto inverso: según Héctor Fix-Zamudio y Jorge Carpizo, ${ }^{6}$ por un lado "el cambio y las modificaciones de la realidad afectan y deben afectar la interpretación de la Constitución", por el otro, "la interpretación es uno de los caminos para adecuar la norma a la realidad, es un esfuerzo para que las normas no caigan avasalladas ante los constantes golpes de la vida". Aunque la interpretación ajustada a los cambios de la vida es menos ostentosa, sale fácilmente a la vista la importancia de la jurisdicción constitucional para hacer viable la democracia.

Las alternativas descritas se observan nítidamente cuando las Constituciones que se introdujeron en tiempos autoritarios enfrentan el cambio de régimen. Así, Chile optó por continuas reformas de la Constitución autoritaria de 1980, acordando en el correr del tiempo

\footnotetext{
${ }^{59}$ Afonso da Silva, J., Poder constituinte e poder popular, Malheiros, Sao Paulo, 2000.

${ }^{60}$ Brewer-Carías, A.R., Golpe de Estado y proceso constituyente en Venequela, UNAM, México, D.F., 2002, y del mismo autor, Estudio sobre la reforma constitucional de 2007, mimeo, aún no publicado, 2007; Combellas, R., Derecho Constitucional. Una introducción al estudio de la Constitución de la República Bolivariana de Venequela, McGraw Hill, Caracas, 2001; Cunarro Conde, E.M., "Agotamiento de los partidos políticos y ciudadanía activa en Venezuela", en Cuestiones Políticas, $N^{\circ}$ 27, 2007, pp. 55-73; Nikken, C., "Sobre la invalidez de una constitución", en Arismendi, A. (comp.), El derecho público a comienzos del siglo XXI. Estudios en homenaje alprofesor Allan Brewer-Carias, 3 tomos, Thompson, Madrid, 2003, tomo 1, pp. 205-218.

${ }^{61}$ Véase al respecto la compilación de estudios de Ferrer Mac-Gregor, E. (coord.), Interpretación constitucional, 2 tomos, Porrúa, UNAM, México, D.F., 2005. En la misma obra véase Häberle, P., "Métodos y principios de la interpretación constitucional. Un catálogo", pp. 673-700.

${ }^{62}$ Carpizo y Fix-Zamudio, "Algunas reflexiones sobre la interpretación constitucional en el ordenamiento mexicano", op. cit., p. 425 y ss.
} 


\section{8 / Dieter Nohlen}

dieciocho reformas constitucionales, hasta llegar a una Constitución democrática, en palabras del presidente Ricardo Lagos, a "[u]na Nueva Constitución [...] acorde con el espíritu de Chile, con el alma permanente de Chile". ${ }^{63}$ En Perú, en cambio, fue la jurisdicción constitucional la que trató de adaptar las normas constitucionales a la realidad, cuando se frustró el proyecto de una reforma constitucional. ${ }^{64}$ Samuel B. Abad Yupanqui" destaca "cómo el aporte del Tribunal Constitucional ha sido determinante para precisar el alcance de lo dispuesto en la Constitución de 1993, e, incluso, para asumir un contenido distinto de la misma que en varios aspectos se ha alejado de la intención de quienes en su momento la elaboraron". ${ }^{66} \mathrm{El}$ Tribunal como máximo intérprete de la Constitución rediseñó la de 1993. "Diversas sentencias han permitido interpretar disposiciones constitucionales en un sentido distinto al otorgado por el constituyente, operándose verdaderas mutaciones constitucionales, con el argumento de adecuar los preceptos constitucionales a las nuevas situaciones sociales". ${ }^{67}$ Aunque no haya una reforma constitucional, la interpretación constitucional y la creación por vía interpretativa de nuevos derechos confieren dinamismo a las normas de la Constitución: concluimos con Gustavo Zegrebelsky ${ }^{68}$ que "la ley de la buena vida de las Constituciones es el desarrollo en la continuidad. El instrumento normal es la jurisprudencia; la reforma es un instrumento excepcional", que en su caso hay que llevar a cabo con criterio y mesura. La continuidad de la Constitución como condición favorable fortalece e intensifica el papel de la jurisdicción constitucional en el proceso de consolidación de la democracia.

\footnotetext{
${ }^{63}$ Ríos Álvarez, L., "La reforma de 2005 a la Constitución chilena”, en Anuario Iberoamericano de Justicia Constitucional, No 10, 2006, pp. 617 y 637.

${ }^{64}$ Véase Landa Arroyo, C., Tribunal constitucional y Estado democrático, $3^{\mathrm{a}}$ edición, Palestra, Lima, 2007, pp. 91 y ss.

${ }^{65}$ Abad Yupanqui, S.B., Constitución y procesos constitucionales, Palestra, Lima, 2005.

${ }^{66}$ Cit. según Anuario Iberoamericano de Justicia Constitucional, 2006, p. 559. Es preciso mencionar también las controversias sobre el nuevo rol del Tribunal Constitucional peruano que resaltan de varias contribuciones de Domingo García Belaúnde, recién incorporadas a su libro El derecho procesal constitucional en perspectiva, Porrúa, México, D.F., 2008.

${ }^{67}$ Ibid., p. 558.

${ }^{68}$ Zagrebelsky, "Jueces constitucionales", op. cit., p. 319.
} 
La tercera condición favorable consiste en la extensión de valores concordantes con el Estado democrático constitucional. Esto se refiere a la cultura democrática y sus normas, ${ }^{69}$ a la cultura de la legalidad, ${ }^{70} \mathrm{a}$ la cultura jurídica ${ }^{71}$ y a la cultura de la jurisdicción constitucional. ${ }^{72}$ En América Latina se observa que en la lucha por el poder la Constitución no alcanza a ser un argumento para mantener encarrilada la acción. A menudo, los actores individuales y colectivos están dispuestos a actuar contra la Constitución, priorizando el objetivo por sobre el procedimiento. Tampoco la permanencia de la Constitución parece importar mucho, pues el proyecto de elaboración de una nueva tiende a rendir políticamente, como demuestran los casos de Venezuela, Bolivia y Ecuador. En el caso ecuatoriano, el Tribunal Constitucional, metido de lleno en el conflicto político, desobedecía incluso a la Constitución que tenía que defender.

En este sentido, Peter Häberle ${ }^{73}$ llama la atención sobre los límites de la defensa jurídica de la Constitución. Extiende la función de ser guardianes de la Constitución a todos los ciudadanos y remite a Konrad Hesse, citándolo: "74 "Una Constitución solamente puede ser protegida políticamente o en la profundidad cultural. Si bien los instrumentos jurídicos son importantes, solamente son eficaces cuando todos poseen una 'voluntad de Constitución' y ésta desenvuelve duraderamente su fuerza normativa". En los tratados de ciencia política se habla de la importancia de la necesaria vitalidad de una sociedad civil que

\footnotetext{
${ }^{69}$ Véase Bertelsmann Stiftung (ed.), Bertelsmann Transformation Index 2006, Bertelsmann Stiftung, Gütersloh, 2005, p. 227; Nohlen, El institucionalismo contextualizado. La relevancia del contexto en el análisis y diseño institucionales, op. cit., pp. 47-52.

${ }^{70}$ Véase Laveaga, G., La cultura de la legalidad, UNAM, México, D.F., 2006.

${ }^{71}$ Véanse Concha Cantú, H.A.; Fix-Fierro, H. \& Valadés, D., Cultura de la Constitución en México. Una encuesta nacional de actitudes, percepciones y valores, UNAM, México, D.F., 2004; Valadés \& Carbonell (coords.), El Estado constitucional contemporáneo. Culturas y sistemas jurídicos comparados, op. cit.

${ }^{72}$ Véase Häberle, El Estado constitucional, op. cit. Asimismo Balaguer Callejón, F. (coord.), Derecho constitucional y cultura, Tecnos, Madrid, 2004.

${ }^{73}$ Ibid., p. 287.

${ }^{74}$ Ibid., p. 286.
} 


\section{0 / Dieter Nohlen}

apoye a la democracia, ${ }^{75}$ o del objetivo de desarrollar una sociedad de ciudadanos, prerrequisito de una democracia de ciudadanos. ${ }^{76}$

Respecto a la democracia ciudadana, conviene comentar que es una visión simpática del futuro de la democracia, fundamentada en el reciente debate social-filosófico europeo, de la cual dista mucho la realidad y especialmente la realidad latinoamericana. La mayoría de los investigadores que transmiten esas ideas a América Latina como modelo y norte de la democracia en esta región, pecan por la falacia de no diferenciar bien entre ideas y contexto, y de allí de desconocer la importancia del contexto que constituye un elemento clave en el desarrollo de tales visiones. ${ }^{77}$ Fíjense sólo en la sociedad civil, su estado y mentalidad en ambos lados del Atlántico. Mientras que florece bien en Europa, en América Latina, en general, es débil su desarrollo, y donde despliega una cierta vida, se caracteriza por actitudes y movilizaciones anti-institucionales. Sus actividades sustraen en última instancia las bases a la democracia en vez de proporcionarle un fundamento seguro. ${ }^{78}$ En resumen, es lindo invocar al ciudadano participante: en el desempeño de sus funciones, la jurisdicción constitucional no puede contar con la sociedad civil como sería oportuno y necesario.

\section{Ambitos de la jurisdiccion constitucional}

Al evaluar la labor y el efecto de la jurisdicción constitucional, es imprescindible diferenciar por ámbitos. Sus incidencias varían por lo demás según el lugar y el tiempo, y conforme a los problemas a los

\footnotetext{
${ }^{75}$ Véase Bertelsmann Stiftung, Bertelsmann Transformation Index 2006, op. cit.

${ }^{76}$ PNUD, Democracy in Latin America. Towards a Citizens' Democracy, op. cit.

${ }^{77}$ Véase Simon, F.B., Einführung in Systemtheorie und Konstruktivismus [Introducción a la teoría sistémica y al constructivismo], Carl-Auer, Heidelberg, 2006, p. 65; respecto a los mecanismos de participación popular véase González Villaseñor, M. I., "El referéndum como sinónimo de soberanía popular y por tanto de participación ciudadana directa”, en Valadés, D. \& Carbonell, M. (coords), El Estado constitucional contemporáneo, UNAM, México, D.F., 2006, pp. 555-571; Moderne, F., "El resurgimiento de los procedimientos de democracia semidirecta en los regímenes presidencialistas de América Latina”, en Anuario Iberoamericano de Justicia Constitucional, $\mathrm{N}^{\circ}$ 6, 2002, pp. 339-359.

${ }^{78}$ Véanse Bertelsmann Stiftung, Bertelsmann Transformation Index 2006, op. cit. p. 228; Nohlen, El institucionalismo contextualizado. La relevancia del contexto en el análisis y diseño institucionales, op. cit., p. 47 y ss.
} 
que la política y el derecho se ven enfrentados. Un buen ejemplo es el estado de emergencia como ámbito de la constitucionalidad. ${ }^{79}$ Es un ámbito muy importante de protección de los derechos fundamentales, pero ocupa a la jurisdicción constitucional sólo cuando el desafío político-militar al interior del país conduce al Ejecutivo a declarar el estado de emergencia (o excepción) como una de las medidas para poder manejar la situación. De esta manera, ha sido un objeto de jurisdicción constitucional sólo en algunos países de América Latina, en especial Colombia. En México sobresale - como en ningún otro país de América Latina - el ámbito electoral. Este hecho —-más allá del problema real que constituye el fenómeno electoral en la vida política del país debido a características político-culturales- se ve fomentado por la inclusión de una gran parte de las reglas del proceso electoral en la propia Constitución. De esta manera, el papel de la jurisdicción constitucional depende también de la amplitud de las materias que la sociedad política quiso que se determinen en la Carta Magna. Podemos concluir que por estas y otras razones las experiencias comparadas son ciertamente disímiles. ${ }^{80}$

Como primer ámbito se impone el de los derechos humanos y fundamentales: ${ }^{81}$ a través de las decisiones de los tribunales constitucionales, la gente percibe que las instituciones le protegen. Pueden apoyar en sembrar una cultura institucional. Dado que cada vez con más frecuencia las Constituciones incluyen en su contenido declaraciones sobre aspectos que persiguen derechos sociales, tales como el derecho al

\footnotetext{
${ }^{79}$ Véase Zovatto, D., Los estados de excepción y los derechos bumanos en América Latina, IIDH - Editorial Jurídica de Venezuela, San José, 1990.

${ }^{80}$ Véase también Acuña, J.M., "Contribuciones de la jurisdicción constitucional para la eficacia jurídica de los derechos sociales en la experiencia comparada", en Revista Iberoamericana de Derecho Procesal Constitucional, $\mathrm{N}^{\circ}$ 6, julio-diciembre 2006, pp. 7 y ss.; Zagrebelsky, op. cit., p. 312 y ss.

${ }^{81}$ Véase la compilación exhaustiva de estudios comparativos y nacionales de Fix-Zamudio, H. \& Ferrer Mac-Gregor, E. (coords.), El derecho de amparo en el mundo, UNAM, Porrúa - Konrad Adenauer Stiftung, México, D.F., 2006; para México en perspectiva comparada, Fix-Zamudio, H. \& Valencia Carmona, S., Derecho Constitucional mexicano y comparado, $4^{a}$ edición, Porrúa - UNAM, México, D.F., 2005. Para Colombia, véase el reciente estudio de Uprimny, R.; Fuentes, A.; Botero, C. \& Jaramillo, J. J. (eds.), Libertad de prensa y derechos fundamentales. Análisis de la jurisprudencia constitucional en Colombia (1992-2005), Fundación Konrad Adenauer, Bogotá, 2006.
} 


\section{2 / Dieter Nohlen}

trabajo, a la seguridad social, a la protección de la salud, a la educación, a la vivienda, etc. ${ }^{82}$ se observa en América Latina una tendencia a admitir el activismo del juez constitucional, que, sin importar su costo, hace efectivos directamente ese tipo de derechos, los cuales afectan también el disfrute de otros derechos considerados fundamentales, como la dignidad y la libertad del ser humano. Esta intromisión en la política es fácilmente comprensible porque no se puede ignorar las expectativas económicas y sociales de la gente si se quiere mantener la condición de norma fundamental que provee las bases a todo el orden jurídico. No obstante, varios constitucionalistas llaman la atención acerca de los límites del intervencionismo social creativo. Carlos Bernal Pulido, ${ }^{83}$ por ejemplo, señala que esta alternativa llevada al extremo parece conducir a deestructurar el Estado, a negar las probabilidades de planeación económica a mediano y largo plazo, y a limitar desmedidamente la democracia representativa. ${ }^{84}$ Jorge Miran$\mathrm{da},{ }^{85}$ por su parte, nos recuerda que el texto de la Constitución tiene su eficacia condicionada por la realidad fáctica, por los hechos concretos de la sociedad, y no está en condiciones de cambiar de inmediato la realidad que tiene que regular. Esto es especialmente cierto en el caso de América Latina, como apunta correctamente José Manuel Acuña ${ }^{86}$ al señalarnos la paradoja consistente en que "los países que más necesitan del desarrollo de los derechos sociales son aquellos en los cuales justamente la jurisdicción constitucional se ve limitada en (la tutela de estos derechos) debido a la asunción consciente de las limitaciones económicas imperantes". Es una de las razones para consentir con Bernal Pulido ${ }^{87}$ que la coerción organizada mediante la jurisdicción constitucional no resulta suficiente para promover el progreso, para construir una sociedad más equitativa, o sea promover

${ }^{82}$ Carpizo, J., Concepto de democracia y sistema de gobierno en América Latina, op. cit., p. 105.

${ }^{83}$ Bernal Pulido, C., "La democracia como principio constitucional en América Latina", en Cuestiones Constitucionales, 17, 2007, p. 51.

${ }^{84}$ Ibíd.

${ }^{85}$ Miranda, J., Constituição e cidadania, Coimbra, Lisboa, 2003, p. 190. Véase también Afonso da Silva, V., "The Limits of Constitutional Law: Public Policies and the Constitution", en Tarabout, G. \& Samaddar, R. (eds.), Conflict, Power and the Landscape of Constitutionalism, Routledge, Londres, 2007, pp. 167-181.

${ }^{86}$ Acuña, "Contribuciones de la jurisdicción constitucional para la eficacia jurídica de los derechos sociales en la experiencia comparada”, op. cit., p. 26 y ss.

87 "La democracia como principio constitucional en América Latina”, op. cit., p. 43. 
la legitimidad de salida y prevenir reveses en el proceso de consolidación de la democracia.

Por último, es imperioso tener en cuenta los efectos empíricos que tiene dicha función social asumida por los jueces, incluyendo los jueces constitucionales. En vez de servir a los más necesitados, es aprovechada por personas que pertenecen, más bien, a la clase media, tienen el necesario acceso a la justicia y saben defender sus intereses. ${ }^{88}$ Estas consideraciones jurídico-sociológicas, que se enfocan en los efectos económicos y sociales de la jurisdicción constitucional, resaltan nuevamente la importancia del contexto en el desempeño jurisdiccional de los tribunales. ${ }^{89}$

Como segundo ámbito se perfila el de la separación de poderes. Se trata de hacer valer uno de los principios fundamentales de la constitucionalidad: que el gobierno es limitado. Empíricamente, ha sido un principio menos respetado en América Latina, no sólo pensando en su completa negación en tiempos autoritarios, sino también en tiempos de democracia. Existe toda una tradición en el presidencialismo latinoamericano de invadir o coaccionar por parte del Ejecutivo a los demás poderes. Respecto a la propia jurisdicción constitucional, conviene recordar lo que hemos ya señalado antes, el constante intento de controlar los respectivos tribunales para impedir su posible papel de jugador veto o para prevenir posibles efectos "perturbadores". Sobran los ejemplos en América Latina. Se destacan últimamente como los más dramáticos Venezuel ${ }^{90}$ y Bolivia. ${ }^{11}$ La conclusión es ambivalente. La constante intromisión confirma la importancia del rol

\footnotetext{
${ }^{88}$ Véase uno de los pocos estudios empíricos sobre este fenómeno a publicarse pronto: Afonso da Silva, V. \& Vargas Terrazas, F., Claiming the Right to Health at Braqlian Courts. The Exclusion of the Already Excluded, tiposcripto, Sao Paulo.

${ }^{89}$ Véase al respecto sobre todo Afonso da Silva, J. Aplicabilidade das normas constitucionais, $3^{\mathrm{a}}$ edición, Malheiros, Sao Paulo, 1998, y del mismo autor, Comentário contextual à constituição, op. cit.

${ }^{90}$ Véase Brewer-Carías, Golpe de Estado y proceso constituyente en Venezuela, op. cit., y Nohlen \& Nohlen, "El sistema electoral alemán y el Tribunal Constitucional Federal. La igualdad electoral a debate - con una mirada a Venezuela", op. cit.

${ }^{91}$ Lazarte, J., Nueva constelación de poder y gobernabilidad, mimeo, La Paz, 2006; Asbún, J., "El control de constitucionalidad en Bolivia: Evolución y perspectivas", en Anuario Iberoamericano de Justicia Constitucional, $\mathrm{N}^{\circ}$ 7, 2003, pp. 7-28.
} 


\section{4 / Dieter Nohlen}

que las demás instituciones, y especialmente el Ejecutivo, conceden a los tribunales constitucionales. Por otra parte, es una muestra de su real debilidad como institución autónoma.

El tercer ámbito es el de las normas electorales. ${ }^{92}$ Lo escogí por su relación íntima con el proceso político mismo y su impacto directo sobre la consolidación de la democracia (relacionada con la legitimidad de entrada, input legitimacy), aunque es un ámbito en general organizado independientemente de los tribunales constitucionales, en órganos autónomos (a veces considerados como cuarto poder). Sin embargo, su labor es similar en cuanto a que tiene que vigilar el proceso electoral y tratar de hacer cumplir las normas constitucionales y legales y proveer justicia electoral. La importancia de la función de la justicia electoral es tanto mayor cuanto más disten de estas normas los valores practicados por los individuos y los grupos de la sociedad ${ }^{93}$

En este sentido, Jesús Orozco Henríquez, ${ }^{94}$ refiriéndose a México, atribuye a la Suprema Corte de Justicia de la Nación "un papel fundamental en la así denominada transición democrática, toda vez que al ser un garante de la regularidad constitucional se ha constituido en un factor de estabilidad y seguridad jurídica". Cabe destacar en este sentido las sentencias del poder judicial de la Federación en materia electoral. La Suprema Corte de Justicia de la Nación en su función de tribunal constitucional ${ }^{95}$ ha resuelto diversos casos sobre distintos aspectos de esta materia: representación proporcional, candidaturas

\footnotetext{
${ }^{92}$ Véase Zovatto, D. \& Orozco Henríquez, J. J. (coords.), Reforma política y electoral en América Latina 1978-1987, UNAM - IDEA Internacional, México, D.F., 2008.

${ }^{93}$ Véase Aina Sadek, M.T., A justicia eleitoral e a consolidação da democracia no Braz̧il, Fundación Konrad Adenauer, Sao Paulo, 1995; Galindo Vácha, J. C., "El control electoral y la intervención del ministerio público en los procesos de nulidad electoral", en Boletín de Derecho Público, N 8, 2007, pp. 113-140.

${ }^{94}$ Orozco Henríquez, J.J., "La Suprema Corte de Justicia de la Nación a partir de 1995 y el nuevo orden constitucional", en Anuario Iberoamericano de Justicia Constitucional, $\mathrm{N}^{\circ} 10,2006$, p. 290. Para la dimensión histórica de la justicia electoral en México véase Tribunal Electoral del Poder Judicial de la Federación, Evolución histórica de las instituciones de la Justicia Electoral en México, Tribunal Electoral del Poder Judicial de la Federación, México, D.F., 2002.

${ }^{95}$ Véase Fix-Zamudio, H., "La Suprema Corte como tribunal constitucional", en Las nuevas bases constitucionales y legales del sistema judicial mexicano. La reforma judicial de 1986, Porrúa, México, D.F., 1987, pp. 345-390.
} 
independientes para ser presidente de la república, o procedimiento para la elección de gobernador interino, entre otros. Así por ejemplo, (a) la acción de inconstitucionalidad 34/2005, presentada por el Partido del Trabajo (PT), que impugnó la Ley Electoral del Estado de Querétaro por considerarla violatoria de los derechos de los partidos políticos minoritarios al aumentar el umbral de 2,5\% a 3\% de la votación total estatal para tener derecho a la asignación de diputados. La Suprema Corte decidió que dicha acción era infundada y reconoció la validez de la Ley declarando que no era violatoria del principio de representación proporcional. (b) Igualmente el amparo en revisión 43/2005 promovido por Jorge Castañeda Gutman en contra de la ley electoral, impugnando el derecho de ser votado previsto en el artículo 35, fracción II, de la Constitucional Federal. Acción que fue sobreseída. (c) Finalmente, la acción de inconstitucionalidad 28/2005 presentada por el Partido de la Revolución Democrática (PRD) que impugnaba las reformas hechas a la Constitución Política del Estado de Colima, las cuales establecían, entre otras cosas, el procedimiento para elección de un gobernador interino, en caso de falta absoluta del gobernador dentro de los primeros dos años de su cargo, y el procedimiento que se seguiría entonces para la elección extraordinaria para un nuevo gobernador. Respecto a lo primero, la Corte desestimó la acción de inconstitucionalidad por no reunir los ocho votos necesarios para conformar la mayoría calificada; respecto a lo segundo, sí declaró la invalidez de las normas que establecían un periodo de tiempo considerado muy breve para la realización de las elecciones extraordinarias.

Por su parte, el Tribunal Electoral del Poder Judicial de la Federación (TEPJF) ha tomado decisiones (a) respecto a las candidaturas independientes, reconociéndoles validez constitucional aunque las leyes electorales ordinarias omiten regular este aspecto, (b) respecto a usos y costumbres en términos de admitir que los comicios se llevan a cabo por usos, costumbres o derecho comunitario, siempre que estos no sean incompatibles con los derechos fundamentales establecidos en la Constitución o instrumentos internacionales suscritos y ratificados por México; (c) respecto a la designación de los integrantes del órgano de dirección de los procesos electorales por 


\section{6 / Dieter Nohlen}

mayoría calificada de la respectiva asamblea legislativa, para evitar que un solo partido político tome la decisión (como ocurrió en Yucatán en 2000-2001); (d) respecto a la financiación de los partidos políticos. El Tribunal decidió que el Instituto Federal Electoral (IFE) sí tiene atribuciones para acceder a la conformación bancaria, fiduciaria y fiscal para funciones de control, vigilancia y sanción del origen de los recursos que reciben los partidos políticos. ${ }^{96}$ Sin embargo, a pesar de toda esta enorme labor para procurar confiabilidad judicial, que debía generar seguridad y certeza jurídica, no ha sido posible que las últimas elecciones generales en México quedaran fuera de cualquier duda y protesta. La reforma electoral aprobada en septiembre de 2007 por ambas cámaras y posteriormente por la mayoría de las legislaturas de las entidades federativas, ampliando nuevamente el ámbito de control constitucional en materia electoral, será un nuevo intento para superar realidades adversas a la consolidación a través del derecho. Sin duda, es este el camino que conviene más, acorde con el concepto europeo, articulado por la Comisión de Venecia del Consejo Europeo, cuyo lema es: democratización por el derecho.

Es bien conocida la frase de Max Weber sobre la esencia de la política práctica, que compara con la perforación de tablones gruesos (Bohren dicker Bretter). Hacer justicia, hacer respetar la Constitución, apoyar a la consolidación de la democracia a través de los medios que son los pertinentes al quehacer jurisdiccional, es frente a los retos de la política, de las demandas económicas y sociales de la gente y de la cultura política de la élite, un proceso duro y paciente comparable al atribuido a la profesión política.

\section{Consideraciones finales}

Al principio de la conferencia nos hemos preguntado si es posible medir el efecto que ejerce la jurisdicción constitucional sobre la consolidación de la democracia. El proceso argumentativo que hemos recorrido para llegar a una suerte de respuesta ha consistido en apuntar, primero, que la consolidación de la democracia depende de

\footnotetext{
${ }^{96}$ Véase Orozco Henríquez, J.J. "Justicia constitucional electoral y democracia en México", en Anuario Iberoamericano de Justicia Constitucional, N 7, 2003, pp. 340 y ss.
} 
muchos otros factores, cada uno de mayor impacto en comparación con nuestra variable jurídico-constitucional; segundo, que el efecto que queremos medir depende del tipo de democracia, así como del aspecto de la consolidación que tenemos en mente. Aplicando el enfoque funcionalista, que pone luz sobre la interacción de las instituciones en el sistema político, hemos indagado más estas dependencias que determinan en mayor o menor grado la actuación y efectividad de los tribunales constitucionales, considerando algunos prerrequisitos irrenunciables y condiciones favorables para que la jurisdicción constitucional pueda cumplir con sus funciones.

En términos metodológicos, podemos afirmar que existe una intensa relación recíproca entre democracia y jurisdicción constitucional. Es la primera generalización que se ha impuesto a lo largo de nuestras consideraciones. Otras se refieren a resultados de contenido. A nivel muy general podemos constatar que el sistema político en el que la jurisdicción constitucional puede alcanzar reales efectos sobre el futuro de la democracia es la democracia constitucional representativa. Este resultado parece de alguna manera trivial. Sin embargo, permite concluir que las tendencias recientes de priorizar la participación directa de los ciudadanos en la toma de decisiones e incluso de sustituir la democracia representativa por la democracia participativa, corren en contra de la constitucionalidad del orden político y así van en detrimento de la función de su protección por parte de los tribunales constitucionales. No hay que equivocarse, el discurso participacionista incluye en su pensar antisistema no sólo las instituciones políticas representativas sino también las judiciales que se perciben como dependientes de ellas.

Otro resultado consiste en que la autoridad de los tribunales constitucionales depende de la autoridad de la Constitución. Esta tesis, nuevamente, suena trivial. Sin embargo, constituye un fuerte antecedente teórico para dudar acerca de la conveniencia de cambiar continuamente la Constitución. La continuidad de la Constitución es en sí misma un alto valor. Sin ella, sería difícil pensar que se pudiera desarrollar una cultura constitucional que según ciertos constitucionalistas sería el mayor aporte a la constitucionalidad de la vida pública. En nuestras 


\section{8 / Dieter Nohlen}

reflexiones sobre la adaptación de las Constituciones a los cambios de tiempo, necesaria para su supervivencia, hemos concluido que las reformas constitucionales tendrían que ser cuidadosas y bien pensadas. Por otra parte, hemos llamado la atención acerca de no subestimar la capacidad de los tribunales constitucionales de interpretar la Constitución según circunstancias cambiantes. Sin este constante ejercicio, y frente al dinamismo del mundo moderno, las Constituciones perderían el contacto con la realidad. Es una labor a menudo no percibida pero de vital importancia para mantener o generar sentimientos de afección con la Constitución y para arraigarla en la conciencia de la gente. Es muy visible y muy apreciada, sin embargo, esta labor, cuando la interpretación de la Constitución de origen autoritario por parte de un tribunal constitucional contribuye a que el país pueda ser gobernado de forma democrática. Como último, hemos destacado el trabajo de los órganos de justicia electoral en garantizar elecciones libres y honestas, un aporte directo a la consolidación de la democracia.

La jurisdicción constitucional tiene efecto sobre la consolidación de la democracia en América Latina, pero lo ejerce sólo sufriendo ella misma el efecto de un sinnúmero de factores que condicionan su quehacer — especialmente el estado de la propia consolidación—. Sólo el enfoque diferenciado nos permite darle el justo peso a la jurisdicción constitucional en la región, aunque va a seguir dependiendo del éxito final de la consolidación. Ex post, las evaluaciones de los logros de la jurisdicción constitucional en Europa tienen un tenor mucho más enfático respecto a la contribución de los tribunales constitucionales a la democracia. Del Tribunal Constitucional alemán se ha dicho: "El Tribunal Constitucional Federal se ha mostrado como el garante más importante de la observación del Derecho constitucional por los demás órganos estatales. La contención del poder político resultante, en favor de la normatividad de la Constitución, ha tenido la trascendencia decisiva de arraigar la Ley Fundamental en la conciencia de la colectividad, participando esencialmente en la consolidación de la nueva estructura estatal". ${ }^{97}$ Espero que en América Latina en un

\footnotetext{
${ }^{97}$ Starck, Ch., "Constitución, jurisdicción constitucional, interpretación constitucional", en Fernández Segado, F. (ed.), The Spanish Constitution in the European Constitutional Context, Dykinson, Madrid, 2003, p. 1158.
} 
futuro no tan lejano el balance de la democracia en su proceso de consolidación así como el de la jurisdicción constitucional en favor de la normatividad constitucional sea similar.

\section{Bibliografía}

Abad Yupanqui, S.B, Constitución y procesos constitucionales, Palestra, Lima, 2005.

Acuña, J.M., "Contribuciones de la jurisdicción constitucional para la eficacia jurídica de los derechos sociales en la experiencia comparada", en Revista Iberoamericana de Derecho Procesal Constitucional, 6, julio-diciembre, 2006, pp. 3-28.

Ahrens, H. \& Nolte, D. (coords.), Rechtsformen und Demokratieentwicklung in Lateinamerika, Vervuert, Francfort, 1999.

Ahumada Ruiz, M., La jurisdicción constitucional en Europa. Bases teóricas y politicas, Universidad de Navarra-Civitas, Navarra, 2005.

Asbún, J., "El control de constitucionalidad en Bolivia: Evolución y perspectivas", en Anuario Iberoamericano de Justicia Constitucional, 7, 2003, pp. 7-28.

Balaguer Callejón, F. (coord.), Derecho constitucionaly cultura, Tecnos, Madrid, 2004.

Begné Guerra, C., Jueces y democracia en México, Miguel Ángel Porrúa, México, D.F., 2007.

Bernal Pulido, C., "La democracia como principio constitucional en América Latina”, en Cuestiones Constitucionales, 17, 2007, pp. 31-51.

Bertelsmann Stiftung (ed.), Bertelsmann Transformation Index 2006, Bertelsmann Stiftung, Gütersloh.

Bobbio, N., Democracy and Dictatorship, Polity Press, Cambridge, 1981.

Bobbio, N., Liberalismo y democracia, Fondo de Cultura Económica, México, D.F., 1985.

Bobbio, N., El futuro de la democracia, Fondo de Cultura Económica, México, D.F., 1996.

Brewer-Carías, A.R., Golpe de Estado y proceso constituyente en Venezuela, UNAM, México, D.F., 2002.

Brewer-Carías, A.R., Estudio sobre la reforma constitucional de 2007 [mimeo, inédito].

Carpizo, J., El presidencialismo méxicano, Siglo XXI, México, D.F., 1978. 


\section{0 / Dieter Nohlen}

Carpizo, J., Concepto de democracia y sistema de gobierno en América Latina, UNAM, México, D.F., 2007.

Carpizo, J. \& Fix-Zamudio, H., "Algunas reflexiones sobre la interpretación constitucional en el ordenamiento mexicano", en Ferrer Mac-Gregor, E. (coord.), Interpretación constitucional, 2 tomos, Porrúa, México, D.F., 2005, tomo 1, pp. 385-438.

Combellas, R., Derecho constitucional. Una introducción al estudio de la Constitución de la República Bolivariana de Venezuela, McGraw Hill, Caracas, 2001.

Concha Cantú, H.A.; Fix-Fierro, H. \& Valadés, D., Cultura de la Constitución en México. Una encuesta nacional de actitudes, percepciones y valores, UNAM, México, D.F., 2004.

Córdova Vianello, L., "La contraposición entre derecho y poder desde la perspectiva del control de constitucionalidad en Kelsen y Schmitt", en Cuestiones Constitucionales, 15, 2006, pp. 47-68.

Cunarro Conde, E.M., "Agotamiento de los partidos políticos y ciudadanía activa en Venezuela”, en Cuestiones Políticas, 37, 2007, pp. 55-73.

Dahl, R.A., Polyarchy. Participation and Opposition, Yale University Press, New Haven, 1971.

Da Silva, J. A. Comentário contextual à constituiçao, Malheoros, Sao Paulo, 2005.

Eguiguren Praeli, F., Los Tribunales Constitucionales en Latinoamérica: una visión comparativa, CIEDLA/ Fundación Konrad Adenauer, Buenos Aires, 2000.

Ferrer Mac-Gregor, E. (coord.), Interpretación Constitucional, 2 tomos, Porrúa/UNAM, México, D.F., 2005.

Fix-Zamudio, H., "La Suprema Corte como tribunal constitucional", en ibidem, Las nuevas bases constitucionales y legales del sistema judicial mexicano. La reforma judicial de 1986, Porrúa, México, D.F., 1987, pp. 345-390.

Fix-Zamudio, H., Justicia constitucionaly judicialización de la política, en Orozco Henríquez, J.J. (coord.), Sistemas de justicia electoral. Evaluación y perspectivas, IFE/PNUD et al., México, 2001, pp. 11-38.

Fix-Zamudio, H. \& Ferrer MacGregor, E. (coords.), El derecho de amparo en el mundo, UNAM, Editorial Porrúa, Konrad Adenauer Stiftung, México, D.F., 2006.

Fix-Zamudio, H. \& Valencia Carmona, S., Derecho constitucional mexicano y comparado, $4^{a}$ ed., Porrúa/UNAM, México, D.F., 2005.

Galindo Vácha, J.C., "El control electoral y la intervención del ministerio 
público en los procesos de nulidad electoral", en Boletín de Derecho Público, 8, 2007, Bogotá, pp. 113-140.

García Belaúnde, D. (coord.), La Constitución y su defensa, Grijley, Lima, 2003.

García Belaúnde, D., El poder judicial en la encrucijada, Ara, Lima, 2004.

García Belaúnde, D., El derecho procesal constitucional en perspectiva, Porrúa, México, D.F., 2008.

García Belaúnde, D. \& Fernández Segado, F. (coords.), La jurisdicción constitucional en Iberoamérica, Dykinsonn et al., Madrid, 1997.

González Villaseñor, M. I., "El referéndum como sinónimo de soberanía popular y por tanto de participación ciudadana directa", en Valadés, D. \& Carbonell, M. (coords.), El Estado constitucional contemporáneo, UNAM, México, D.F., 2006, pp. 555-571.

Graciarena, J. \& Franco, R., Social Formation and Power Structures in Latin America, Sage, Londres - Beverly Hills, 1978.

Habermas, J., Problemas de legitimación en el capitalismo tardío, Amorrortu, Buenos Aires, 1989.

Häberle, P., El Estado constitucional, UNAM, México, D.F., 2001.

Häberle, P., "La Constitución 'en el contexto' ”, en Anuario Iberoamericano de Justicia Constitucional, 2003, pp. 223-246.

Häberle, P., "Métodos y principios de la interpretación constitucional. Un catálogo", en Ferrer Mac-Gregor, E. (coord.), Interpretación constitucional, Porrúa, México, D.F., 2005, tomo 1, pp. 673-700.

Heidorn, J., Legitimität und Regierbarkeit, Dunckler \& Humblot, Berlín, 1982.

Hermet, G., Elpueblo contra la democracia, Instituto de Estudios Económicos, Madrid, 1989.

Hermet, G., En las fronteras de la democracia, Fondo de Cultura Económica, México, 1996.

Jaguaribe, H., Political Development. A General Theory and a Latin American Case Study, Harper \& Row, New York, 1973.

Jesse, E. \& Nohlen, D., "Presidencialismo/Sistema presidencial", en Nohlen et al., Diccionario de Ciencia Política. Teorías, métodos, conceptos, Porrúa, México, D.F. 1114-1117.

Lamounier, B., "Brazil: Inequalities against Democracy", en Diamond, L. et al. (eds.), Democracy in Developing Countries: Latin America, Lynne Rienner, Boulder, 1999, pp. 131-189.

Latinobarómetro 1996-2006, entregas anuales, Santiago de Chile. 


\section{2 / Dieter NohLen}

Laveaga, G., La cultura de la legalidad, UNAM, México, D.F., 2006.

Lazarte, J., Bolivia. Nueva constelación de poder y gobernabilidad, La Paz, 2006 [mimeo].

Linz, J.J. \& Stepan, A., Problems of Democratic Transition and Consolidation, Johns Hopkins University Press, Baltimore, 1996.

Linz, J.J. \& Valenzuela, A. (eds.), The Failure of Presidential Democracy, 2 vols, Johns Hopkins University Press, Baltimore - Londres, 1994.

Lösing, N., Die Verfassungsgerichtsbarkeit in Lateinamerika, Nomos, BadenBaden, 2001 (existe versión castellana bajo el extraño título: La jurisdiccionalidad constitucional en Latinoamérica, Dykinson, Konrad Adenauer Stiftung, Madrid, 2002).

Luhmann, N., Soziale Systeme, Suhrkamp, Frankfurt, 1984.

Macpherson, C.B., La democracia liberal y su época, Alianza, Madrid, 1982.

Maturana, H. \& Varela, F., Der Baum der Erkenntnis, Scherz, Bern, 1984.

Midlarsky, M. I. (ed.), Inequality, Democracy, and Economic Development, Cambridge University Press, Cambridge, 1997.

Miranda, J., Constituiçao e cidadania, Coimbra, Lisboa, 2003.

Moderne, F., "El resurgimiento de los procedimientos de democracia semidirecta en los regímenes presidencialistas de América Latina", en Anuario Iberoamericano de Justicia Constitucional, 6, 2002, pp. 339-359.

Morlino, C., "Consolidación democrática. Definición, modelos, hipótesis", en Revista Española de Investigaciones Sociológicas, 35, 1986, pp. 7-61.

Nikken, C., "Sobre la invalidez de una Constitución", en: Arismendi, A. (comp.), El derecho público a comienzos del siglo XXI. Estudios en homenaje al profesor Allan Brewer-Carías, 3 tomos, Thompson, Madrid, 2003, tomo 1, pp. 205-218.

Nogueira Alcalá, H. (coord.), Jurisdicción constitucional en Chile y América Latina: presente y perspectiva, LexisNexis, Santiago, 2005.

Nohlen, D., El contexto hace la diferencia, UNAM, México, D.F., 2003.

Nohlen, D., Sistemas electorales y partidos politicos, $3^{\mathrm{a}}$ ed., Fondo de Cultura Económica, México, D.F., 2004.

Nohlen, D., El institucionalismo contextualizado. La relevancia del contexto en el análisis y diseño institucionales, Porrúa/UNAM, México, D.F., 2006.

Nohlen, D., "La renovación del presidencialismo: reformas institucionales y gobernabilidad democrática", en El institucionalismo contextualizado. La relevancia del contexto en el análisis y diseño institucionales, Porrúa/UNAM, México, DF, pp. 67-80. 
Nohlen, D., Derecho y politica en su contexto, UNAM et. al., México, D.F., 2008.

Nohlen, D. et al., Diccionario de Ciencia Politica. Teorías, métodos, conceptos, 2 tomos, Porrúa - El Colegio de Veracruz, México, 2006.

Nohlen, D. \& Fernández, M. (eds.), Presidencialismo versus parlamentarismo. América Latina, Editorial Nueva Sociedad, Caracas, 1991.

Nohlen, D. \& Fernández, M. (eds.), El presidencialismo renovado, Nueva Sociedad, Caracas, 1998.

Nohlen, D.; Zovatto, D.; Orozco, J. \& Thompson, J. (coords.), Tratado de derecho electoral comparado de América Latina, Fondo de Cultura Económica, México, D.F., 2007.

Nohlen, D. \& Nohlen, N. “El sistema electoral alemán y el Tribunal Constitucional Federal. La igualdad electoral a debate - con una mirada a Venezuela", en Revista de Derecho Público, 109, enero-marzo, 2007, Caracas, pp. 7-26.

Núñez Muñoz, I. K., "La ciudadanía y su desempeño en los sistemas políticos democráticos”, en Cuestiones Políticas, 37, 2007, pp. 36-54.

Orozco Henríquez, J.J., "Justicia constitucional electoral y democracia en México", en Anuario Iberoamericano de Justicia Constitucional, 7, 2003, pp. 329-344.

Orozco Henríquez, J.J., "La Suprema Corte de Justicia de la Nación a partir de 1995 y el nuevo orden constitucional", en Anuario Iberoamericano de Justicia Constitucional, 10, 2006, pp. 281- 302.

Ortiz Ortiz, R., "Contextos, instituciones y actores políticos. Dieter Nohlen y el estudio de las instituciones políticas en América Latina", en: Nohlen, D., El institucionalismo contextualizado. La relevancia del contexto en el análisis y diseño institucionales, Porrúa/UNAM, México, D.F., 2006, pp. 1-30.

Ortiz Ortiz, R. \& Reynoso Nuñez, J., "Dieter Nohlen y el estudio de la democracia y las instituciones políticas en América Latina", en López Rubí Calderón, J. R. (coord.), Política y ciencia política en Dieter Noblen, Benemérita Universidad Autónoma de Puebla, Puebla, 2007, pp. 17-57.

Palomino Manchego, J.F. (coord.), El derecho procesal constitucional peruano. Estudios en homenaje a Domingo García Belaunde, 2 tomos, Grijley, Lima, 2005.

Pasquino, G., Modernización y desarrollo político, Nova Terra, Barcelona, 1974. 


\section{4 / Dieter Nohlen}

Payne, J.M.; Zovatto, D.; Carrillo Flórez, F. \& Allamand, A., La política importa. Democracia y desarrollo en América Latina, Banco Interamericano de Desarrollo, Washington, D.C., 2003.

Programa de las Naciones Unidas para el Desarrollo (PNUD), Democracy in Latin America. Towards a Citizens' Democracy, Aguilar et al., Buenos Aires, 2004.

Putnam, R. D., Making Democracy Work: Civil Traditions in Modern Italy, Princeton University Press, Princeton, 1993.

Ríos Álvarez, L., "La reforma de 2005 a la Constitución chilena", en Anuario Iberoamericano de Justicia Constitucional, 10, 2006, pp. 617-637.

Salazar Ugarte, P., La democracia constitucional. Una radiografía teórica, Fondo de Cultura Económica - UNAM, México, D.F., 2000.

Sagués, N.P., El tercer poder. Notas sobre el perfil político del poder judicial, Lexis Nexis, Buenos Aires, 2005.

Schedler, A., "Los cálculos de consolidación democrática”, en Republicana. Política y Sociedad, 1 (1), 2002, pp. 5-25.

Simon, F.B., Einführung in Systemtheorie und Konstruktivismus, Carl-Auer, Heidelberg, 2006.

Spencer-Brown, G., Laws of Form, Allen \& Unwin, Londres, 1969.

Starck, Ch. (ed.), Constitutionalism, Universalism and Democracy. A Comparative Analysis, Nomos, Baden-Baden, 1999.

Starck, Ch. "Constitución, jurisdicción constitucional, Interpretación constitucional", en Fernández Segado, F. (ed.), The Spanish Constitution in the European Constitutional Context, Dykinson, Madrid, 2003, pp. 1157-1178.

Sternberger, D., Lebende Verfassung, Verlag Anton Hain, Meisenheim, 1956.

Touraine, A., ¿Podemos vivir juntos?, Fondo de Cultura Económica, Buenos Aires, 1997.

Uprimny, R.; Fuentes, A.; Botero, C. \& Jaramillo, J. F., Libertad de prensa y derechos fundamentales. Análisis de la jurisprudencia constitucional en Colombia (1992-2005), Fundación Konrad Adenauer et al., Bogotá, 2006.

Valadés, D., El control del poder, Fondo de Cultura Económica, México, D.F., 1998.

Valadés, D., Constitución y democracia, UNAM, México, D.F., 2000.

Valadés, D., La parlamentarización de los sistemas presidenciales, UNAM, México, D.F., 2007. 
Valadés, D. (ed.), Gobernabilidady constitucionalismo en América Latina, UNAM, México, D.F., 2005.

Valadés, D. \& Carbonell, M. (coords.), El Estado constitucional contemporáneo. Culturas y sistemas jurídicos comparados, 2 tomos, UNAM, México, D.F., 2006.

Viola, F., La democracia deliberativa entre constitucionalismo y multiculturalismo, UNAM, México, D.F., 2006.

Zagrebelsky, G., "Jueces constitucionales”, en Revista Iberoamericana de Derecho Procesal Constitucional, 6, 2006, pp. 311- 324.

Zilla, C., "Los conceptos en el enfoque politológico de Dieter Nohlen", en López Rubí Calderón, J. R. (coord.), Política y ciencia política en Dieter Noblen, Benemérita Universidad Autónoma de Puebla, Puebla, 2007, pp. 75-100.

Zovatto, D., Los estados de excepción y los derechos humanos en América Latina, IIDH/ Editorial Jurídica de Venezuela, San José, 1990.

Zovatto, D., "Las instituciones de democracia directa", en Nohlen, D.; Zovatto, D.; Orozco, J. \& Thompson, J. (comps.), Tratado de derecho electoral comparado de América Latina, $2^{a}$ ed., Fondo de Cultura Económica, México, D.F., 2007, pp. 134-161. 